BMJ Open

Diabetes

Research

\& Care

\title{
Anemia and incidence of dementia in patients with new-onset type 2 diabetes: a nationwide population-based cohort study
}

\author{
Jae Woo Choi, ${ }^{1}$ Tae Hyun Kim (D) , ${ }^{2}$ Euna Han (D) ${ }^{1}$
}

To cite: Choi JW, Kim TH, Han E. Anemia and incidence of dementia in patients with new-onset type 2 diabetes: a nationwide populationbased cohort study. BMJ Open Diab Res Care 2020;8:e001289. doi:10.1136/ bmjdrc-2020-001289

- Additional material is published online only. To view please visit the journal online (http://dx.doi.org/10.1136/ bmjdrc-2020-001289).

THK and EH contributed equally.

Received 16 February 2020 Revised 9 June 2020 Accepted 27 June 2020

\section{Check for updates}

(c) Author(s) (or their employer(s)) 2020. Re-use permitted under CC BY-NC. No commercial re-use. See rights and permissions. Published by BMJ.

${ }^{1}$ College of Pharmacy, Yonsei University, Incheon, Korea (the Republic of)

${ }^{2}$ Graduate School of Public Health, Yonsei University, Seoul, Korea (the Republic of)

Correspondence to Dr Euna Han; eunahan@yonsei.ac.kr and Dr Tae Hyun Kim;

thkim@yuhs.ac

\section{ABSTRACT}

Introduction This study aimed to examine the association between anemia and the incidence of dementia in patients with new-onset type 2 diabetes.

Research design and methods This study used the Korean National Health Insurance Service-Health Screening Cohort and included 32590 participants aged $\geq 40$ years who were diagnosed with new-onset type 2 diabetes between 2004 and 2007 and followed up until 2013. Anemia was defined according to the criteria provided by the WHO, hemoglobin $<120 \mathrm{~g} / \mathrm{L}$ for women and $<130 \mathrm{~g} / \mathrm{L}$ for men, and was measured from after diagnosis date of type 2 diabetes to 2007. Dementia was defined by the Classification of Diseases 10th revision code as primary diagnosis and was measured from after hemoglobin measurement to 2013. We calculated the adjusted HR (AHR) and $95 \% \mathrm{Cl}$ to assess the risk of dementia using multivariable Cox proportional hazards regression models. Results We identified 1682 patients who developed dementia within a 7.5-year follow-up. Among patients with type 2 diabetes, patients with anemia were associated with an increased risk of dementia than those without anemia (AHR, $1.21 ; 95 \% \mathrm{Cl} 1.06$ to 1.39). Patients with mild (AHR, $1.18 ; 95 \% \mathrm{Cl} 1.03$ to 1.38) and moderate (AHR, $1.39 ; 95 \% \mathrm{Cl} 1.06$ to 1.83 ) anemia were associated with an increased risk of dementia than those without anemia among patients with type 2 diabetes. Men (AHR, 1.47; $95 \% \mathrm{Cl} 1.16$ to 1.83 ) and middle-aged adults (AHR, 1.31; $95 \% \mathrm{Cl} 1.03$ to 1.75 ) with anemia were associated with an increased risk of dementia than their counterparts without anemia among patients with type 2 diabetes.

Conclusions Our findings suggest that anemia is significantly associated with an increased risk of dementia among patients with newly diagnosed type 2 diabetes.

\section{INTRODUCTION}

Type 2 diabetes and dementia are main chronic conditions with increasing prevalence in Korea and worldwide and are anticipated to have considerable effects on the aging population. ${ }^{1-4}$ Previous evidence suggests that type 2 diabetes is related to a decline in cognitive function and the incidence of dementia. ${ }^{5-11}$ It has been hypothesized that insulin resistance and hyperglycemia affect cerebrovascular pathologies; however, the underlying

\section{Significance of this study}

What is already known about this subject?

- Type 2 diabetes is associated with an increased incidence of dementia.

- Anemia frequently occurs in patients with type 2 diabetes and is associated with a decline in cognitive function and increased risk of developing dementia.

What are the new findings?

- Among patients with newly diagnosed type 2 diabetes, patients with anemia were associated with an increased risk of dementia than those without anemia.

- Among patients with type 2 diabetes, patients with mild or moderate anemia were independently associated with a higher incidence of dementia than those without anemia

- Among patients with type 2 diabetes, men and middle-aged adults with anemia were associated with an increased risk of developing dementia than their counterparts without anemia.

How might these results change the focus of research or clinical practice?

- Anemia is a modifiable factor, and careful survey and optimal management of this disease in patients with type 2 diabetes may be a helpful and applicable way to prevent dementia partially.

mechanisms remain unclear. $^{12}{ }^{13}$ Furthermore, the number of people with dementia is increasing rapidly and is estimated to reach 82 million in 2030 and 152 million in $2050 .^{14}$ Although dementia has important economic and social implications and the total global social cost for managing dementia was estimated to be US $\$ 818$ billion in $2015,{ }^{15}$ there is no specific treatment for dementia in patients with type 2 diabetes. It is, therefore, significant to explore the risk factors for incident dementia among patients with type 2 diabetes.

Anemia has been defined as having hemoglobin concentration lower than $130 \mathrm{~g} / \mathrm{L}$ and $120 \mathrm{~g} / \mathrm{L}$ in men and women, respectively. ${ }^{16}$ 
There is an increasing interest regarding the role of anemia in the development of dementia in the general population. ${ }^{16-25}$ A chronic brain hypo-oxygenation due to anemia could be the biological mechanism underlying this association. ${ }^{17} \mathrm{~A}$ significant reduction in brain oxygenation results in reversible cognitive impairment ${ }^{26}$; conversely, an increase in the circulating blood oxygen levels improves cognitive performance. A double-blind, placebo-controlled study implied improvement in cognitive performance following oxygen administration. ${ }^{27}$

Previous studies evaluating the association between anemia and dementia have been performed in general $^{16212225}$ or specific population, such as patients with chronic kidney disease $(\mathrm{CKD})^{23}$ or in older adults, ${ }^{17-20} 24$ but data on the relationship between anemia and the risk of incident dementia in patients with type 2 diabetes are limited. Anemia frequently occurs in patients with type 2 diabetes, ${ }^{28}$ and previous study reported that the risk of anemia in patients with diabetes is approximately two to three times higher than that of a general population. ${ }^{29}$ The underlying mechanisms may be due to features of the diabetic milieu (systemic inflammation, functional hematinic deficiencies, resistance of bone marrow to erythropoietin, and red cell abnormalities) that cause hemoglobin levels to drop. ${ }^{30}$ Considering that patients with diabetes may be more vulnerable to anemia and that anemia was a major risk factor for dementia, the evidence for association between anemia and dementia among patients with type 2 diabetes needed to be investigated.

This study, therefore, aimed to examine the association between anemia and the incidence of dementia in patients with newly diagnosed type 2 diabetes using nationwide population-based cohort data. We also aimed to identify the risk of dementia development according to the severity of anemia and explore the relationship between anemia and incidence of dementia stratified by sex and age groups.

\section{MATERIALS AND METHODS}

Data and study sample

We used data from the Korean National Health Insurance Service-Health Screening Cohort (NHIS-HEALS) database. ${ }^{31}$ The NHIS is the sole insurance provider in Korea and covers almost all citizens. All enrollees of the insurance system aged $\geq 40$ years are entitled to standard medical examinations biennially that include a questionnaire survey on lifestyle and medical history, height, weight, and blood pressure (BP) measurements, and laboratory tests. The NHIS-HEALS data were obtained from the 2002-2003 health screening participants who were aged between 40 and 79 years in 2002 and were followed up until 2013. The NHIS-HEALS consisted of 514866 health screening participants, who accounted for approximately $10 \%$ of all health screening participants in 2002 and 2003 by simple random sampling. This database includes patients' demographic characteristics and clinical information concerning treatments, diagnoses, and prescribed drugs of all visits (outpatient, inpatients, and pharmacy visits) provided by healthcare facilities. Moreover, it is connected to the Korean death registration database, which includes dates and causes of deaths.

Of the 513268 patients who were included in the 20042007 NHIS-HEALS database, we excluded those with type 1 diabetes from 2002 to 2007 ( $\mathrm{n}=6629)$. Moreover, we excluded patients without type 2 diabetes to enroll those who were diagnosed with type 2 diabetes from 2004 to 2007 as study participants $(\mathrm{n}=425161)$. Type 2 diabetes $(n=81478)$ was defined as the existence of at least one of the following criteria: (1) fasting blood glucose level of $\geq 126 \mathrm{mg} / \mathrm{dL}$ ( $7 \mathrm{mmol} / \mathrm{L})$, (2) at least one additional diagnosis of type 2 diabetes within 6 months from the initial date of diagnosis under the ICD-10 codes E11-E14, and (3) use of oral hypoglycemic agents or insulin. In subjects who were diagnosed with type 2 diabetes between 2004 and 2007 (baseline period), we excluded those who were diagnosed with type 2 diabetes before the baseline period to recruit only those with newly diagnosed type 2 diabetes $(\mathrm{n}=40914)$. Additionally, we excluded study patients who had a history of dementia before hemoglobin measurement to minimize reverse causality $(\mathrm{n}=176)$ and individuals who had no health screening data after diabetes diagnosis $(\mathrm{n}=7792)$ or missing data regarding hemoglobin $(n=6)$. The final study sample included 32590 patients with new-onset type 2 diabetes (online supplementary figure 1 ).

\section{Measurement}

The outcome variable in this study is dementia. Dementia was measured by ICD-10 codes (F00, F01, F02, F03, G30, or G31) as primary diagnosis ${ }^{32}$ and was measured from after hemoglobin measurement between 2004 and 2007 until December 31, 2013. This definition of dementia incidence was applied to outpatients and inpatients.

We used anemia as the independent variable, which was defined according to the WHO criteria, hemoglobin $<120 \mathrm{~g} / \mathrm{L}$ for women and $<130 \mathrm{~g} / \mathrm{L}$ for men,${ }^{33}$ and anemia was measured from after diagnosis date of type 2 diabetes to 2007 . The severity of anemia was categorized as mild (hemoglobin $\geq 110 \mathrm{~g} / \mathrm{L}$ ), moderate (hemoglobin $80-109 \mathrm{~g} / \mathrm{L}$ ), or severe (hemoglobin $<80 \mathrm{~g} / \mathrm{L}$ ) according to the WHO criteria. Serum hemoglobin concentration was estimated using the cyanmethemoglobin method.

Potential confounding factors were age, sex, body mass index (BMI), systolic and diastolic BP, fasting glucose, total cholesterol, smoking, heavy drinking, exercise, household income, residential area, and comorbidities. The potential confounding factors except for comorbidities were measured on the date of hemoglobin measurement, while comorbidities were measured by screening information for all medical records from January 1, 2002 to the date of hemoglobin measurement. Age was measured as time scale in the Cox proportional hazards models. BP was estimated with the individuals seated following at least $5 \mathrm{~min}$ of rest. Total cholesterol and fasting glucose were estimated by blood samples following 
overnight fasting. The participants were divided into the following age groups: middle-aged (40-64 years) and older adults ( $\geq 65$ years). The WHO recommendations for Asian populations were used to categorize individuals into five BMI groups: $<18.5 \mathrm{~kg} / \mathrm{m}^{2}$ (underweight), $18.5-22.9 \mathrm{~kg} / \mathrm{m}^{2} \quad$ (normal), $23.0-24.9 \mathrm{~kg} / \mathrm{m}^{2} \quad$ (overweight), $25.0-29.9 \mathrm{~kg} / \mathrm{m}^{2}$ (class I obese), or $\geq 30 \mathrm{~kg} / \mathrm{m}^{2}$ (class II obese). ${ }^{34}$ Regarding smoking status, participants were classified as current smokers, ex-smokers, or nonsmokers. Individuals who consumed $\geq 30 \mathrm{~g} /$ day of alcohol were classified as heavy drinkers. ${ }^{35}$ Exercise was defined as performing exercise at least once a week. Household income was classified as follows: (1) low income $(<40$ th percentile), (2) middle income (41st-80th percentile),

Table 1 General characteristics of the study participants according to incidence of anemia

\begin{tabular}{|c|c|c|c|c|c|c|}
\hline \multirow[b]{3}{*}{ Variables } & \multirow[b]{3}{*}{ Total } & \multicolumn{4}{|c|}{ Anemia } & \multirow[b]{3}{*}{$P$ value } \\
\hline & & \multicolumn{2}{|l|}{ Yes } & \multicolumn{2}{|l|}{ No } & \\
\hline & & $\mathbf{n}$ & $\%$ & $\mathbf{n}$ & $\%$ & \\
\hline Total & 32590 & 3104 & 9.5 & 29486 & 90.5 & \\
\hline Women & 12040 & 1731 & 55.8 & 10309 & 35.0 & $<0.001$ \\
\hline Age (years) & & & & & & $<0.001$ \\
\hline $40-64$ & 24635 & 1771 & 57.1 & 22864 & 77.5 & \\
\hline$\geq 65$ & 7955 & 1333 & 42.9 & 6622 & 22.5 & \\
\hline $\mathrm{BMI}\left(\mathrm{kg} / \mathrm{m}^{2}\right)$ & & & & & & $<0.001$ \\
\hline$\leq 18.5$ & 609 & 177 & 5.7 & 432 & 1.5 & \\
\hline $18.5-23$ & 8985 & 1278 & 41.2 & 7707 & 26.1 & \\
\hline $23-25$ & 8645 & 719 & 23.2 & 7926 & 26.9 & \\
\hline $25-30$ & 12769 & 840 & 27.1 & 11929 & 40.5 & \\
\hline$\geq 30$ & 1582 & 90 & 2.9 & 1492 & 5.1 & \\
\hline \multicolumn{7}{|l|}{$\mathrm{BP}(\mathrm{mm} \mathrm{Hg})$} \\
\hline Systolic & $130.8 \pm 17.1$ & 127.7 & 17.8 & 131.1 & 17.0 & $<0.001$ \\
\hline Diastolic & $81.0 \pm 11.0$ & 77.6 & 11.1 & 81.4 & 10.9 & $<0.001$ \\
\hline Fasting glucose (mg/dL) & $132.6 \pm 46.3$ & 129.4 & 49.2 & 132.9 & 46.0 & $<0.001$ \\
\hline Total cholesterol (mg/dL) & $202.5 \pm 40.7$ & 190.2 & 41.5 & 203.8 & 40.4 & $<0.001$ \\
\hline Current smokers & 7297 & 469 & 15.1 & 6828 & 23.2 & $<0.001$ \\
\hline Heavy drinkers & 2007 & 128 & 4.1 & 1879 & 6.4 & $<0.001$ \\
\hline Exercisers & 15177 & 1208 & 38.9 & 13969 & 47.4 & $<0.001$ \\
\hline Household income & & & & & & $<0.001$ \\
\hline Low & 10155 & 1184 & 38.1 & 8971 & 30.4 & \\
\hline Middle & 12461 & 1070 & 34.5 & 11391 & 38.6 & \\
\hline High & 9974 & 850 & 27.4 & 9124 & 30.9 & \\
\hline Residential area & & & & & & $<0.001$ \\
\hline Metropolitan & 4825 & 383 & 12.3 & 4442 & 15.1 & \\
\hline Urban & 8962 & 843 & 27.2 & 8119 & 27.5 & \\
\hline Rural & 18803 & 1878 & 60.5 & 16925 & 57.4 & \\
\hline \multicolumn{7}{|l|}{ Comorbidities } \\
\hline Hypertension & 15048 & 1527 & 49.2 & 13521 & 45.9 & $<0.001$ \\
\hline Dyslipidemia & 11666 & 1141 & 36.8 & 10525 & 35.7 & 0.240 \\
\hline CKD & 245 & 56 & 1.8 & 189 & 0.6 & $<0.001$ \\
\hline Ischemic heart disease & 5339 & 625 & 20.1 & 4714 & 16.0 & $<0.001$ \\
\hline Stroke & 1725 & 240 & 7.7 & 1485 & 5.0 & $<0.001$ \\
\hline Depressive disorders & 2990 & 395 & 12.7 & 2595 & 8.8 & $<0.001$ \\
\hline Cancer & 2522 & 397 & 12.8 & 2125 & 7.2 & $<0.001$ \\
\hline
\end{tabular}

Values are presented as mean \pm SD or $\mathrm{n}(\%)$.

$\mathrm{BMI}$, body mass index; BP, blood pressure; CKD, chronic kidney disease. 
or (3) high income (81st-100th percentile). Residential area was classified as metropolitan (capital), urban (local government with $>1$ million residents), or rural (otherwise). Comorbidities included hypertension (ICD10: I10-I15), dyslipidemia (ICD-10: E78), CKD (ICD-10: N18), stroke (ICD-10: I60-I63), ischemic heart disease (ICD-10: I20-I25), depressive disorders (ICD-10: F32F33), and cancer (ICD-10: C00-C99).

\section{Statistical analysis}

Patients' demographic and clinical characteristics were compared according to the presence of anemia using an independent t-test for continuous variables and Pearson's $\chi^{2}$ test for categorical variables, respectively. Data are expressed as mean $\pm \mathrm{SD}$ for continuous variables or as numbers with percentages for categorical variables. We measured age-standardized incidence rates $(95 \% \mathrm{CI})$ of dementia per 1000 person-years according to presence or severity of anemia. For each study participant, risk of dementia was estimated from the date of hemoglobin measurement after diabetes diagnosis between 2004 and 2007 until December 31, 2013. The length of follow-up was measured in days, and all study participants were followed up until the onset of dementia, withdrawal from the insurance system, death from any causes, or the end of 2013, whichever occurred first.

We calculated the adjusted HR (AHR) and 95\% CI to determine the association between anemia and the incidence of dementia using Cox proportional hazards regression models. First, we analyzed the effect of anemia on the incidence of dementia in patients with new-onset type 2 diabetes. Second, we also identified the risk of dementia according to the severity of anemia. Finally, we explored the relationship between anemia and the incidence of dementia stratified by sex and age groups.

All data extraction and statistical analyses were performed using SAS V.9.4 software. Proportional hazards assumptions were evaluated statistically and satisfied for all models.

\section{RESULTS}

Our study enrolled 32590 patients with new-onset type 2 diabetes aged $\geq 40$ years and observed 1682 events of dementia during an average of $7.5 \pm 1.7$ years of follow-up. Table 1 shows the general characteristics of the study participants according to the severity of anemia. The proportions of women $(55.8 \%$ vs $35.0 \%)$, older adults $(42.9 \%$ vs $22.5 \%)$, underweight participants $(5.7 \%$ vs $1.5 \%)$, participants with low household income $(38.1 \%$ vs $30.4 \%)$, participants living in rural areas $(60.5 \%$ vs $57.4 \%)$, and participants with comorbidities (hypertension $(49.2 \%$ vs $45.9 \%)$, CKD $(1.8 \%$ vs $0.6 \%)$, ischemic heart disease $(20.1 \%$ vs $16.0 \%)$, stroke $(7.7 \%$ vs $5.0 \%)$, depressive disorders $(12.7 \%$ vs $8.8 \%)$, and cancer ( $12.8 \%$ vs $7.2 \%)$ ) with anemia were significantly higher than those without anemia among patients with type 2 diabetes. The average systolic (127.7 $\mathrm{mm} \mathrm{Hg}$ vs $131.1 \mathrm{~mm} \mathrm{Hg}$ ) and diastolic $(77.6 \mathrm{~mm}$ $\mathrm{Hg}$ vs $81.4 \mathrm{~mm} \mathrm{Hg}) \mathrm{BP}$, fasting glucose $(129.4 \mathrm{mg} / \mathrm{dL}$ vs $132.9 \mathrm{mg} / \mathrm{dL})$, and total cholesterol $(190.2 \mathrm{mg} / \mathrm{dL}$ vs $203.8 \mathrm{mg} / \mathrm{dL}$ ) and the proportions of current smokers $(15.1 \%$ vs $23.2 \%)$, heavy drinkers $(4.1 \%$ vs $6.4 \%)$, and exercisers $(38.9 \%$ vs $47.4 \%)$ with anemia were significantly lower than those without anemia among patients with type 2 diabetes.

Table 2 presents the AHR and 95\% CI for the incidence of dementia according to the presence and severity of anemia among patients with newly diagnosed type 2 diabetes. After adjusting for sex and age, model 1 showed that patients with anemia were at a higher risk of dementia (AHR, 1.35; 95\% CI 1.18 to 1.53 ) than those without anemia among patients with type 2

Table 2 Association between anemia and incidence of dementia in patients with new-onset type 2 diabetes

\begin{tabular}{|c|c|c|c|c|c|c|c|c|}
\hline Model & Variables & $\mathbf{n}$ & Events & $\begin{array}{l}\text { Person- } \\
\text { years }\end{array}$ & $\begin{array}{l}\text { Age-standardizec } \\
\text { incidence rates } \\
(95 \% \mathrm{Cl}) \text { of } \\
\text { dementia per } \\
1000 \text { person- } \\
\text { years }\end{array}$ & HR (95\% Cl) & Model $2 \ddagger$ & Model 3§ \\
\hline \multirow[t]{2}{*}{ Model 1} & Anemia & & & & & & & \\
\hline & No & 29486 & 1396 & 221429 & 43 (41 to 45$)$ & 1.00 & & \\
\hline \multirow[t]{5}{*}{ Model 2} & Severity of & anemia & & & & & & \\
\hline & None & 29486 & 1396 & 221429 & 43 (41 to 45$)$ & 1.00 & & \\
\hline & Mild & 2484 & 224 & 17618 & 71 (64 to 78 ) & $1.32(1.13 \text { to } 1.51)^{\star \star \star}$ & $1.30(1.11 \text { to } 1.49)^{\star \star}$ & $1.18(1.03 \text { to } 1.38)^{\star}$ \\
\hline & Moderate & 584 & 61 & 3972 & 81 (65 to 98$)$ & $1.58(1.21 \text { to } 2.05)^{\star \star \star}$ & $1.55(1.24 \text { to } 2.01)^{\star \star \star}$ & $1.39(1.06 \text { to } 1.83)^{\star}$ \\
\hline & Severe & 36 & 1 & 238 & 43 (1 to 87$)$ & 0.69 (0.11 to 5.07$)$ & 0.63 (0.11 to 4.74$)$ & 0.68 (0.10 to 4.87$)$ \\
\hline
\end{tabular}

${ }^{*} \mathrm{P}<0.05,{ }^{* *} \mathrm{P}<0.01,{ }^{* * *} \mathrm{P}<0.001$.

†HRs were estimated after adjusting for sex and age.

†HRs were estimated after adjusting for sex, age, household income, and residential area.

§HRs were estimated after adjusting for sex, age, body mass index, blood pressure, fasting glucose, total cholesterol, smoking, heavy alcohol drinking, exercise, household income, residential area, and comorbidities. 


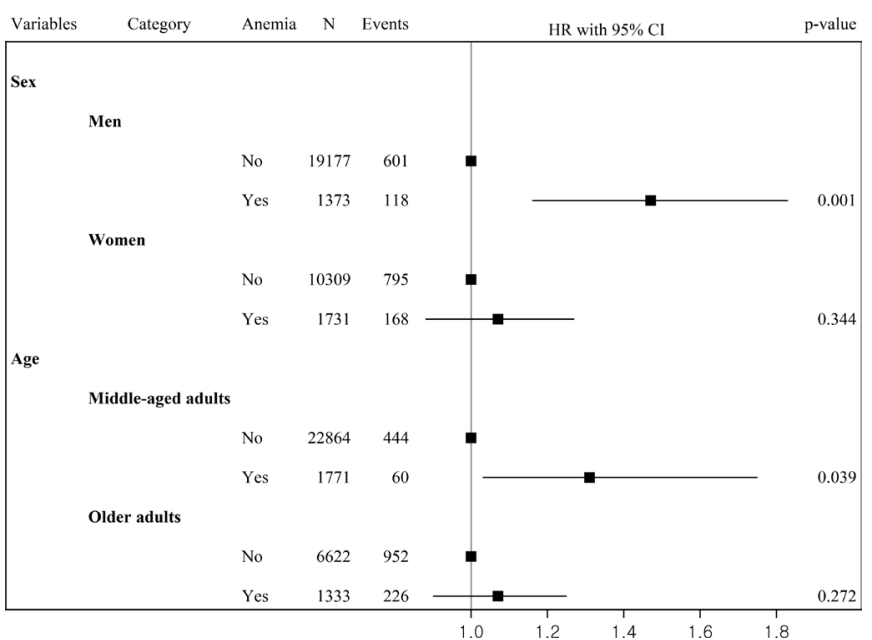

Figure 1 Association between anemia and incidence of dementia according to sex and age.

diabetes. Among patients with type 2 diabetes, the risk of dementia was significantly higher in patients with mild (AHR, 1.32; 95\% CI 1.13 to 1.51 ) and moderate (AHR, $1.58 ; 95 \%$ CI 1.21 to 2.05 ) anemia than those without anemia. After adjusting for sex, age, residential area, and household income, model 2 revealed that patients with anemia were at a higher risk of dementia (AHR, 1.33; $95 \%$ CI 1.12 to 1.51 ) than those without anemia among patients with type 2 diabetes. Among patients with type 2 diabetes, the risk of dementia was significantly higher in patients with mild (AHR, 1.30; 95\% CI 1.11 to 1.49) and moderate (AHR, 1.55; 95\% CI 1.24 to 2.01 ) anemia than those without anemia. After adjusting for all potential confounding factors, model 3 indicated that patients with anemia were at a higher risk of dementia (AHR, 1.21; $95 \%$ CI 1.06 to 1.39 ) than those without anemia among patients with type 2 diabetes. Among patients with type 2 diabetes, the risk of dementia was significantly higher in patients with mild (AHR, 1.18; 95\% CI 1.03 to 1.38) and moderate (AHR, 1.39; 95\% CI 1.06 to 1.83 ) anemia than those without anemia. However, there was no significant association between severe anemia and risk of developing dementia in all models.

Figure 1 shows the results of the analysis of the association between anemia and the incidence of dementia according to sex and age. Among men with type 2 diabetes, patients with anemia were at a higher risk of dementia (AHR, 1.47; 95\% CI 1.16 to 1.83 ) than those without anemia. In middle-aged adults with type 2 diabetes, the risk of dementia increased significantly in patients with anemia than those without (AHR, 1.31; $95 \%$ CI 1.03 to 1.75 ). In women and older adults, there was no statistically significant association between anemia and the incidence of dementia.

\section{DISCUSSION}

This study had three main findings. First, among patients with newly diagnosed type 2 diabetes, patients with anemia were associated with an increased risk of dementia than those without anemia. Second, among patients with type 2 diabetes, patients with mild or moderate anemia were associated with an increased risk of dementia development than those without anemia. Third, among patients with type 2 diabetes, men and middle-aged adults with anemia were associated with an increased risk of dementia than their counterparts without anemia.

Our findings were in line with previous studies which had investigated the association between anemia and dementia, ${ }^{16-22} 2425$ except for a research on patients with CKD.$^{23}$ Although the mechanisms linking anemia to the incidence of dementia have not been fully established, a few hypotheses have been suggested. First, chronic brain hypoxia associated with anemia may affect patients' cognitive function by expediting the accumulation of amyloid- $\beta .^{36}$ Second, anemia has been related to the progression of white matter disease. ${ }^{37} \mathrm{~A}$ meta-analysis study showed a significant relationship between white matter hyperintensities and the incidence of dementia. Finally, anemia associated with deficiency in micronutrients such as vitamin $\mathrm{B}_{12}$ and iron may be related to dementia. ${ }^{20}$ Iron deficiency (a mineral that plays a critical role in storage and transport of oxygen in the brain) may cause cognitive decline or cerebral hypoxia. ${ }^{38}$ Deficiency in vitamin $B_{12}$ has also been associated with dementia. ${ }^{39}$

Our findings showed that patients with mild or moderate anemia had higher incidence of dementia than those without anemia. Furthermore, the agestandardized incidence rate of dementia of moderate anemia (0.081) was higher than that of mild anemia (0.071). Previous research verified that patients with lower hemoglobin concentration had a higher AHR value of incident dementia. ${ }^{17}$ Another study showed that severe anemia was independently related to the incidence of dementia. ${ }^{24}$ These findings support the notion that the risk of developing dementia increases when the hemoglobin concentration decreases. One potential mechanism that can possibly explain the dose-response association is that mild anemia may have lesser effect on oxygen delivery to the brain through a compensatory reaction, such as vascular dilation, to maintain the cerebral blood flow than moderate or severe anemia. ${ }^{40}$

Although the prevalence of anemia and dementia is more frequent in women than in men, ${ }^{24}$ our findings showed that anemia was independently associated with the incidence of dementia in men with type 2 diabetes, which is different from results in previous studies conducted in the general population. Denny et $a l^{18}$ suggested that the effect of anemia on dementia is greater in women than in men. Chung $e t a l^{21}$ found that female, and not male, patients with dementia had higher prevalence of iron deficiency anemia. Our results also showed a significant association between anemia and the incidence of dementia in middle-aged adults with type 2 diabetes. Anemia and dementia commonly occur in older adults, ${ }^{414}$ and previous studies showed significant relationship between anemia and dementia among older adults. ${ }^{17-20} 24$ In patients with type 2 diabetes, our 
findings suggest that men and middle-aged adults with anemia were significantly associated with risk of dementia compared with their counterparts without anemia, respectively.

Our study had several limitations that need to be considered. First, we could not determine the severity of dementia from the medical records. Second, although we examined the incidence of dementia according to the severity of anemia, only one case of severe anemia was associated with incidence of dementia. Future research is warranted to explore the association between severe anemia and dementia using larger data. Third, although we excluded patients with a dementia diagnosis made before the date of anemia measurement, there may have been reverse causality. Fourth, we were not able to obtain patients' genetic information, such as APOE4 carrier status, and we were not able to assess their education and literacy levels, which might have an effect on cognitive function. ${ }^{43}$ Finally, as the Korean population is predominantly of Asian descent, further studies are needed to confirm that these findings are consistent with other ethnicities and geographical regions.

Despite these limitations, the strengths of our study included its longitudinal design and the abundant available data regarding demographics, lifestyle variables, comorbidities, and biomedical information. To the best of our knowledge, this is the first study to examine the association between anemia and the incidence of dementia among patients with new-onset type 2 diabetes.

In conclusion, this cohort study of the Korean population demonstrated that anemia is significantly associated with an increased risk of dementia among patients with newly diagnosed type 2 diabetes. Anemia is a modifiable factor, and most of its types occur due to insufficient nutrition (vitamins or iron). ${ }^{44}$ Moreover, anemia of chronic disease may be modified through treatment (eg, erythropoietin therapy in diabetes). ${ }^{45}$ Therefore, we suggest that careful examination and optimal management of anemia in patients with type 2 diabetes may be helpful and applicable methods to partially prevent the development of dementia.

Acknowledgements We would like to thank Editage (www.editage.co.kr) for providing English language editing assistance.

Contributors JWC and EH designed the study. JWC and THK performed the literature review and interpretation of data analysis. JWC analyzed the data. JWC, THK, and EH wrote the draft. All authors read and approved the final manuscript.

Funding This work was supported by the National Research Foundation of Korea (grant number: 2019R1A2C1003259, 2019K2A9A2A08000108, and 2020R111A1A01053104).

\section{Competing interests None declared.}

Patient consent for publication Not required.

Ethics approval The Yonsei University Institutional Review Board approved this study (approval number: 7001988-202002-HR-792-01E) and the requirement for informed consent was waived as the NHIS-HEALS database was constructed after anonymization according to strict confidentiality guidelines.

Provenance and peer review Not commissioned; externally peer reviewed.

Data availability statement Data may be obtained from a third party and are not publicly available.
Open access This is an open access article distributed in accordance with the Creative Commons Attribution Non Commercial (CC BY-NC 4.0) license, which permits others to distribute, remix, adapt, build upon this work non-commercially, and license their derivative works on different terms, provided the original work is properly cited, appropriate credit is given, any changes made indicated, and the use is non-commercial. See: http://creativecommons.org/licenses/by-nc/4.0/.

ORCID iDs

Tae Hyun Kim http://orcid.org/0000-0003-1053-8958

Euna Han http://orcid.org/0000-0003-2656-7059

\section{REFERENCES}

1 Cheng D, Noble J, Tang MX, et al. Type 2 diabetes and late-onset Alzheimer's disease. Dement Geriatr Cogn Disord 2011;31:424-30.

2 Snowden MB, Steinman LE, Bryant LL, et al. Dementia and cooccurring chronic conditions: a systematic literature review to identify what is known and where are the gaps in the evidence? Int $J$ Geriatr Psychiatry 2017;32:357-71.

3 Shin J-Y. Trends in the prevalence and management of diabetes in Korea: 2007-2017. Epidemiol Health 2019;41:e2019029.

$4 \mathrm{Kim}$ YJ, Han JW, So YS, et al. Prevalence and trends of dementia in Korea: a systematic review and meta-analysis. J Korean Med Sci 2014;29:903-12.

5 Grodstein F, Chen J, Wilson RS, et al. Type 2 diabetes and cognitive function in community-dwelling elderly women. Diabetes Care 2001;24:1060-5.

6 Yaffe K, Blackwell T, Kanaya AM, et al. Diabetes, impaired fasting glucose, and development of cognitive impairment in older women. Neurology 2004;63:658-63.

7 Roberts RO, Geda YE, Knopman DS, et al. Association of duration and severity of diabetes mellitus with mild cognitive impairment. Arch Neurol 2008;65:1066-73.

8 Peila R, Rodriguez BL, Launer LJ, et al. Type 2 diabetes, APOE gene, and the risk for dementia and related pathologies: the Honolulu-Asia aging study. Diabetes 2002;51:1256-62.

9 Xu WL, Qu CX, Wahlin A, et al. Diabetes mellitus and risk of dementia in the Kungsholmen project: a 6-year follow-up study. Neurology 2004;63:1181-6.

10 Luchsinger JA, Tang MX, Stern Y, et al. Diabetes mellitus and risk of Alzheimer's disease and dementia with stroke in a multiethnic cohort. Am J Epidemiol 2001;154:635-41.

11 Davis WA, Zilkens RR, Starkstein SE, et al. Dementia onset, incidence and risk in type 2 diabetes: a matched cohort study with the Fremantle diabetes study phase I. Diabetologia 2017;60:89-97.

12 Luchsinger JA. Adiposity, hyperinsulinemia, diabetes and Alzheimer's disease: an epidemiological perspective. Eur $J$ Pharmacol 2008;585:119-29.

13 Luchsinger JA. Type 2 diabetes and cognitive impairment: linking mechanisms. J Alzheimers Dis 2012;30 Suppl 2:S185-98.

14 Matsumoto C, Ogawa $\mathrm{H}$, Saito $\mathrm{Y}$, et al. Sex difference in effects of low-dose aspirin on prevention of dementia in patients with type 2 diabetes: a long-term follow-up study of a randomized clinical trial. Diabetes Care 2020;43:314-20.

15 World Health Organization. Fact sheets, dementia, 2020. Available: http://www.who.int/en/news-room/fact-sheets/detail/dementia

16 Schneider ALC, Jonassaint C, Sharrett AR, et al. Hemoglobin, anemia, and cognitive function: the Atherosclerosis risk in Communities study. J Gerontol A Biol Sci Med Sci 2016;71:772-9.

17 Atti AR, Palmer K, Volpato S, et al. Anaemia increases the risk of dementia in cognitively intact elderly. Neurobiol Aging 2006;27:278-84.

18 Denny SD, Kuchibhatla MN, Cohen HJ. Impact of anemia on mortality, cognition, and function in community-dwelling elderly. $\mathrm{Am}$ $J$ Med 2006;119:327-34.

19 Deal JA, Carlson MC, Xue Q-L, et al. Anemia and 9-year domainspecific cognitive decline in community-dwelling older women: the women's health and aging study II. J Am Geriatr Soc 2009;57:1604-11.

20 Hong CH, Falvey C, Harris TB, et al. Anemia and risk of dementia in older adults: findings from the health ABC study. Neurology 2013;81:528-33.

21 Chung S-D, Sheu J-J, Kao L-T, et al. Dementia is associated with iron-deficiency anemia in females: a population-based study. $J$ Neurol Sci 2014;346:90-3.

22 Faux NG, Rembach A, Wiley J, et al. An anemia of Alzheimer's disease. Mol Psychiatry 2014;19:1227-34.

23 Kurella Tamura M, Vittinghoff E, Yang J, et al. Anemia and risk for cognitive decline in chronic kidney disease. BMC Nephrol 2016;17:13. 
24 Jeong S-M, Shin DW, Lee JE, et al. Anemia is associated with incidence of dementia: a national health screening study in Korea involving 37,900 persons. Alzheimers Res Ther 2017;9:94.

25 Wolters FJ, Zonneveld HI, Licher S, et al. Hemoglobin and anemia in relation to dementia risk and accompanying changes on brain MRI. Neurology 2019;93:e917-26.

26 Croughwell ND, Newman MF, Blumenthal JA, et al. Jugular bulb saturation and cognitive dysfunction after cardiopulmonary bypass. Ann Thorac Surg 1994;58:1702-8.

27 Scholey AB, Moss MC, Neave N, et al. Cognitive performance, hyperoxia, and heart rate following oxygen administration in healthy young adults. Physiol Behav 1999;67:783-9.

28 Thomas MC, Tsalamandris C, Maclsaac RJ, et al. The epidemiology of hemoglobin levels in patients with type 2 diabetes. Am J Kidney Dis 2006;48:537-45.

29 Thomas MC, Maclsaac RJ, Tsalamandris C, et al. Unrecognized anemia in patients with diabetes: a cross-sectional survey. Diabetes Care 2003;26:1164-9.

30 Thomas MC. Anemia in diabetes: marker or mediator of microvascular disease? Nat Clin Pract Nephrol 2007;3:20-30.

31 Seong SC, Kim Y-Y, Park SK, et al. Cohort profile: the National health insurance Service-National health screening cohort (NHIS-HEALS) in Korea. BMJ Open 2017;7:e016640.

32 Wucherer D, Eichler T, Kilimann I, et al. Antidementia drug treatment in people screened positive for dementia in primary care. $J$ Alzheimers Dis 2015;44:1015-21.

33 World Health Organization. Nutritional anemias: reports of a who scientific group. Geneva: World Health Organisation, 1968.

34 WHO Expert Consultation. Appropriate body-mass index for Asian populations and its implications for policy and intervention strategies. Lancet 2004;363:157-63.
35 Agarwal DP. Cardioprotective effects of light-moderate consumption of alcohol: a review of putative mechanisms. Alcohol Alcohol 2002;37:409-15

36 Zhang X, Le W. Pathological role of hypoxia in Alzheimer's disease. Exp Neurol 2010;223:299-303.

37 Inzitari M, Studenski S, Rosano C, et al. Anemia is associated with the progression of white matter disease in older adults with high blood pressure: the cardiovascular health study. J Am Geriatr Soc 2008;56:1867-72.

38 Yavuz BB, Cankurtaran M, Haznedaroglu IC, et al. Iron deficiency can cause cognitive impairment in geriatric patients. J Nutr Health Aging 2012;16:220-4.

39 Moore E, Mander A, Ames D, et al. Cognitive impairment and vitamin B12: a review. Int Psychogeriatr 2012;24:541-56.

40 Borgström L, Jóhannsson H, Siesjö BK. The influence of acute normovolemic anemia on cerebral blood flow and oxygen consumption of anesthetized rats. Acta Physiol Scand 1975;93:505-14.

41 Lobo A, Launer LJ, Fratiglioni L, et al. Prevalence of dementia and major subtypes in Europe: a collaborative study of population-based cohorts. Neurology 2000;54:S4-9.

42 Izaks GJ, Westendorp RG, Knook DL. The definition of anemia in older persons. JAMA 1999;281:1714-7.

43 Farmer ME, Kittner SJ, Rae DS, et al. Education and change in cognitive function. The epidemiologic catchment area study. Ann Epidemiol 1995;5:1-7.

44 Kassebaum NJ, Jasrasaria R, Naghavi M, et al. A systematic analysis of global anemia burden from 1990 to 2010. Blood 2014:123:615-24.

45 Nakatsuka K, Hino M, Miki T, et al. Erythropoietin treatment for anemia in end-stage renal disease with diabetes mellitus. Diabetes Care 1990;13:1130-1. 